\title{
SACCULINA BEAUFORTI AND LOXOTHYLACUS IHLEI, TWO RHIZOCEPHALA OF THE CRAB SCYLLA SERRATA (FORSK.)
}

BY

\author{
H. BOSCHMA
}

Rijksmuseum van Natuurlijke Historie, Leiden

With great pleasure I dedicate the two new species described below to the two Amsterdam zoologists Prof. L. F. De Beaufort and Prof. J. E. W. Ihle, who with their important researches in various branches of zoology both have so largely contributed to the progress of this science.

The two species described here are parasites of Scylla serrata (Forsk.); they are the only specimens until now known to infest this species of Portunid crab.

\section{Sacculina beauforti nov. spec.}

Sandakan Bay, Borneo; seine, March 2, I908, U. S. Bureau of Fisheries, "Albatross" Philippine Expedition 1907-I908 (from the collection of the United States National Museum, Washington, D. C.); I ex. on Scylla serrata (Forsk.).

The specimen (fig. Ia) is of more or less rectangular shape; its surface show.s a few grooves and wrinkles, but otherwise appears smooth to the naked
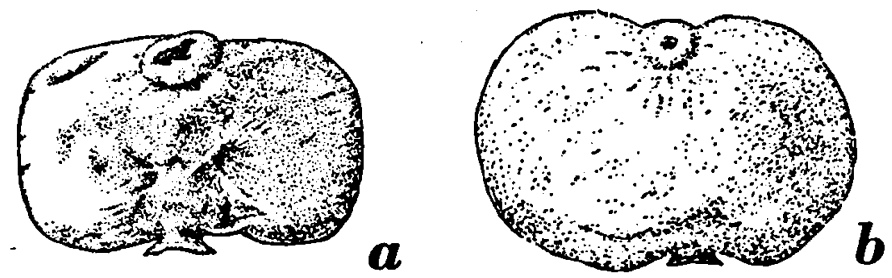

Fig. 1. a, Sacculina beauforti nov. spec., left side. $b$, Loxothylacus ihlei nov. spec., left side. $a, \times 1 ; b, \times I^{1} / 3$.

eye. The mantle opening lies at the anterior bonder of the left side; it is surrounded by a well developed sphincter. The dimensions of the specimen are 35 by 22 by $13 \mathrm{~mm}$. 


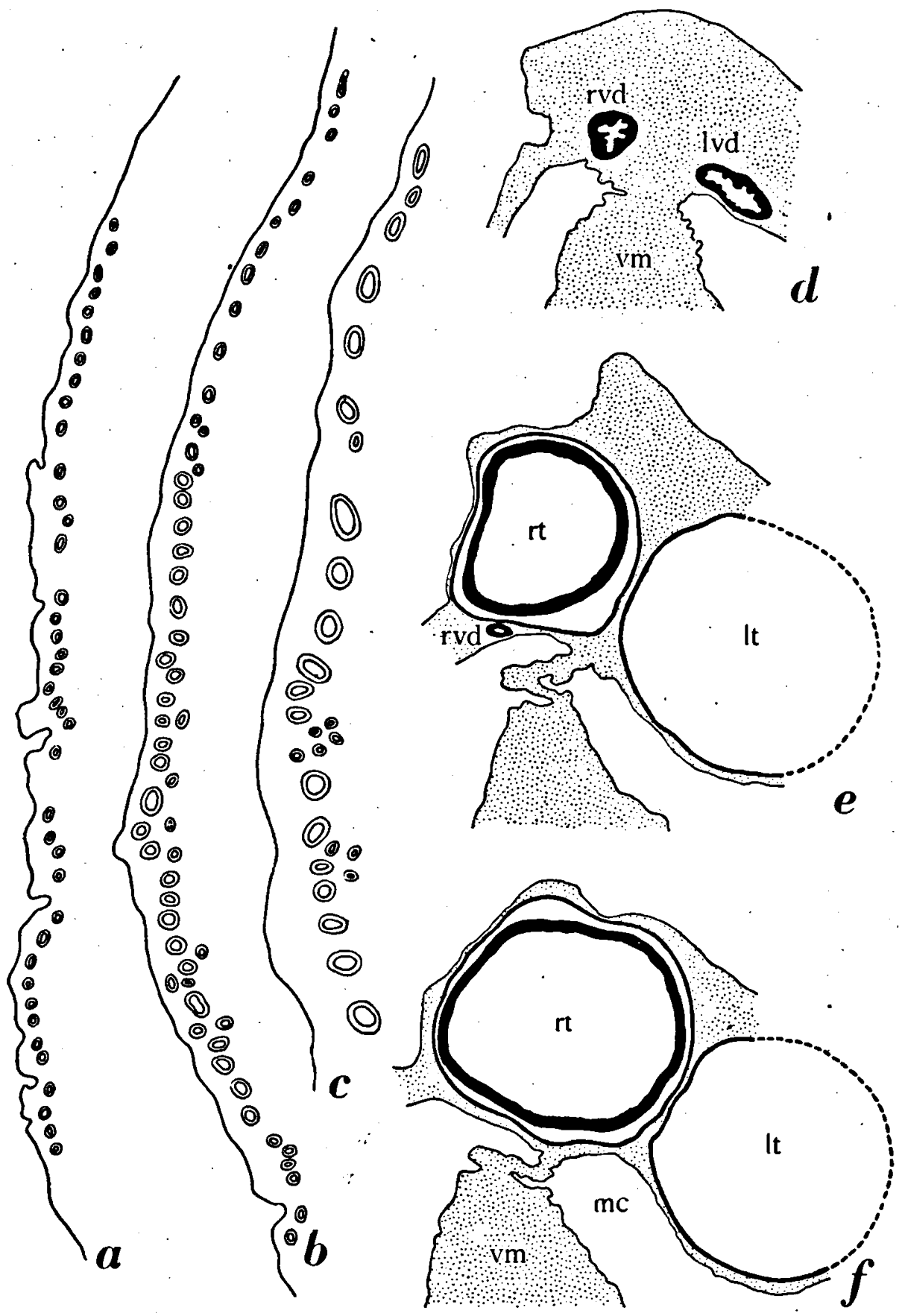

Fig. 2. Sacculina beauforti nov. spec. $a-c$, longitudinal sections of the right colleteric gland (anterior part of $c$ with 6 canals, omitted); $a$ from a rather peripheral part, each following section from a more central region. $d-f$, longitudinal sections of the posterior part of the body; $d$ from the central region, each following section from a more dorsal part. lt, left testis; $l v d$, left vas deferens; $m c$, mantle cavity; $r t$, right testis; rvd, right vas deferens; $v m$, visceral mass. $a-c, \times 36 ; d-f, \times 9$. 
Before sections were made of the posterior part of the body and the visceral mass, the greater part of the mantle was cut of $f$. In doing this, unfortunately one of the testes became badly damaged, so that in the sections only the muscular sheath surrounding this testis is remaining. Notwithstanding this, however, a distinct description of the shape of the male organs can be given.

In their ventral part the vasa deferentia are comparatively wide, though their lumen is somewhat restricted on account of ridges on their inner walls (fig. $2 d$ ). Further dorsally the vasa deferentia gradually become narrower ( $r v d$ in fig. $2 e$ ). The testes are globular and rather voluminous (fig. $2 e, f$ ). The whole complex of the male organs is found in the posterior part of the body, outside the visceral mass.

The colleteric glands are of large size and extremely flattened. Their canal system is more or less arranged in one row parallel to the surface of the visceral mass (fig. $2 a-c$ ). The sections represented in the present paper show 40 (fig. $2 a$ ), 56 (fig. $2 b$ ), and 34 canals (fig. $2 c$; in this figure 6 of these canals are not drawn, as the anterior part was omitted for lack of space).

The external cuticle of the mantle is comparatively thick, as in many parts
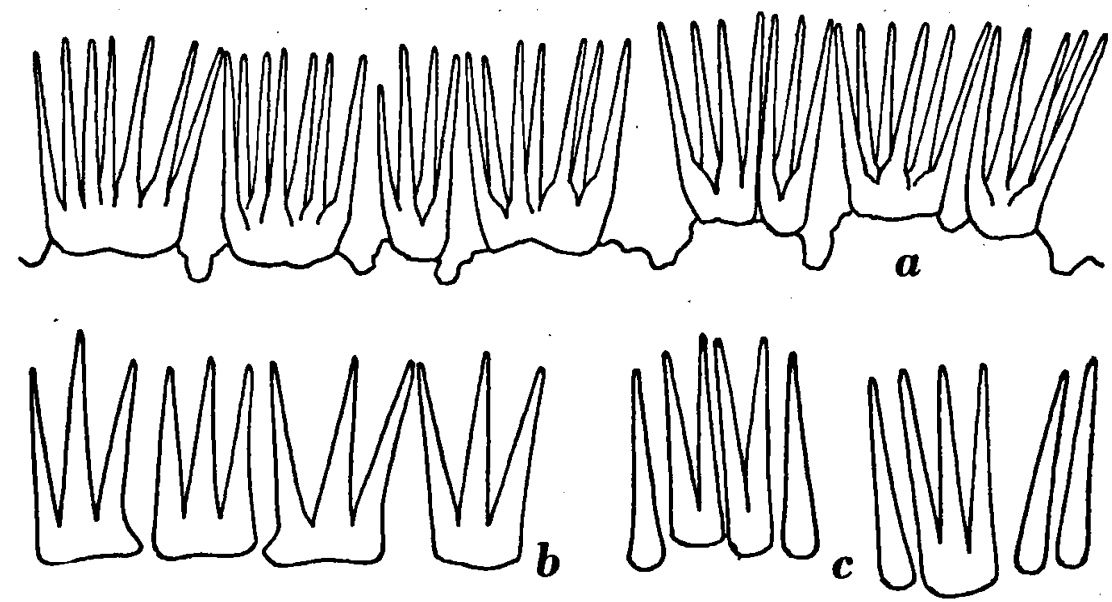

Fig. 3. Sacculina beauforti nov. spec. $a-c$, excrescences from various parts of the external cuticle. $\times 530$.

it reaches a thickness of $\mathrm{I} 20 \mu$. Its surface is covered with groups of hyaline spines which as a rule are united on common basal parts. In some parts of the cuticle the number of spines in each group is comparatively large (fig. $3 a$ ), then the spines themselves are rather thin. In other parts of the cuticle the groups consist of a smaller number of spines (fig. $3^{b}$ ), whilst then the spines themselves may be rather thick. In again other parts of the cuticle the spines have a tendency to not unite into definite groups (fig. $3 \mathrm{c}$ ). In the greater part of the mantle the height of the excrescences varies from 35 to $46 \mu$.

Though large parts of the internal cuticle of the mantle were examined to 
find retinacula these could not be found. In all probability therefore these excrescences are not occurring in the species.

The male organs of Sacculina beauforti in every important detail correspond exactly with those of Sacculina leptodiae Guér.-Gan. Moreover the excrescences of the external cuticle are of a shape as often found in specimens of $S$. leptodiae. The chief difference of the two species is that of the colleteric glands. In $S$ : beauforti these are extremely large and contain numerous canals (more than 50 in a longitudinal section of the most strongly branched region), whilst in $S$. leptodiae the colleteric glands are of a rather small size and contain comparatively few canals only (less than 20 in a longitudinal section of the most strongly branched region). A large number of specimens of S. leptodiae has been examined in this respect, and as in this species the structure of the colleteric glands is constantly of the same character, the peculiar appearance of these glands in $S$. beauforti safely may be regarded as a distinct specific character.

\section{Loxothylacus ihlei nov. spec.}

Aroe Islands, Tissot van Patot leg. et don. (from the collection of the Zoological Museum at Amsterdam); I ex. on Scylla serrata (Forsk.).

The specimen (fig. I $b$ ) is of a more or less oval, somewhat panduriform shape; its surface does not show any pronounced grooves or wrinkles. The narrow mantle opening lies at the anterior border of the left side, it is surrounded by a fairly well developed sphincter. The dimensions of the specimen are 30 by 19 by $9 \mathrm{~mm}$.

A series of longitudinal sections of the visceral mass (fig. $4 a-f$ ) shows, that the male genital organs possess a distinct curvature in an anterior direction. The vasa deferentia (fig. 4 a) are rather wide; their inner wall has numerous ridges. The testes are strikingly different in size; the left is very little developed and remains narrow (fig. $4 c, d$ ), whilst the right has enlarged into a voluminous pouch (fig. $4 b-f$ ). The extreme ventral end of the right testis shows a division into two parts by a short septum (fig. $4 a$ ).

The colleteric glands are large; they contain a very great number of canals. In a section of one of the colleteric glands, from the region in which the canal system has its most strongly branched appearance, I68 of these canals may be counted (fig. $4 g$ ).

The external cuticle, which in various parts of the mantle has a thickness of 7 to $25 \mu$, on its surface bears excrescences which consist of a hyaline kind of chitin, differing from that of the main layers. In surface view these excrescences appear as round or oval papillae with denticulated upper marginal parts (fig. $5 \mathrm{a}$ ). In sections of the cuticle the excrescences are seen to consist of more or less cylindrical small papillae, which on their upper margin possess small spines (fig. $5 b, c$ ); in some regions the spines, probably as a result of 

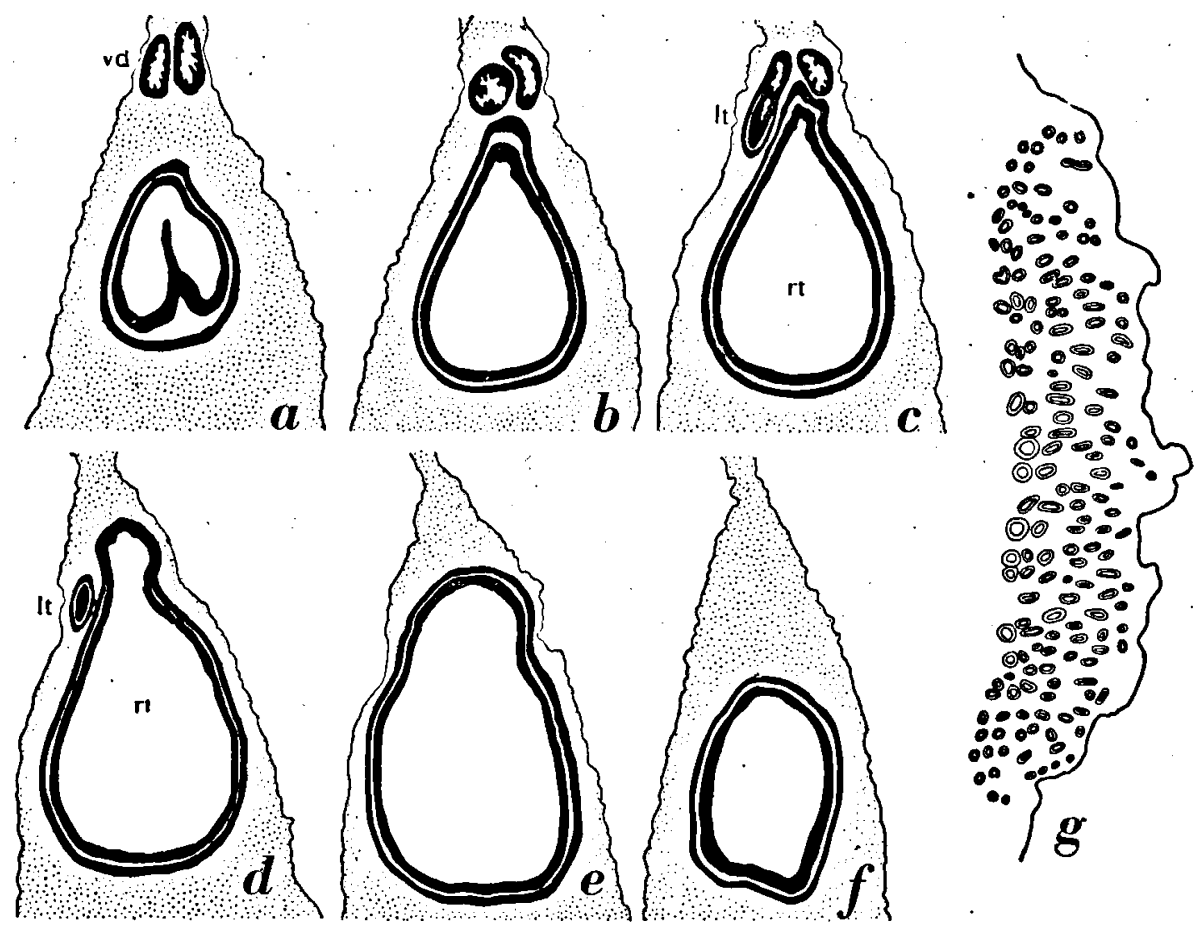

Fig. 4. Loxothylacus ihlei nov. spec. $a-f$, longitudinal sections of the posterior part of the visceral mass; $a$ through the ventral parts of the male genital organs, each following section from a more dorsal region. $g$, longitudinal section of the right colleteric gland. $l t$, left testis; $r t$, right testis; $v d$, vasa deferentia. $a-f, \times 10 ; g, \times 26$.

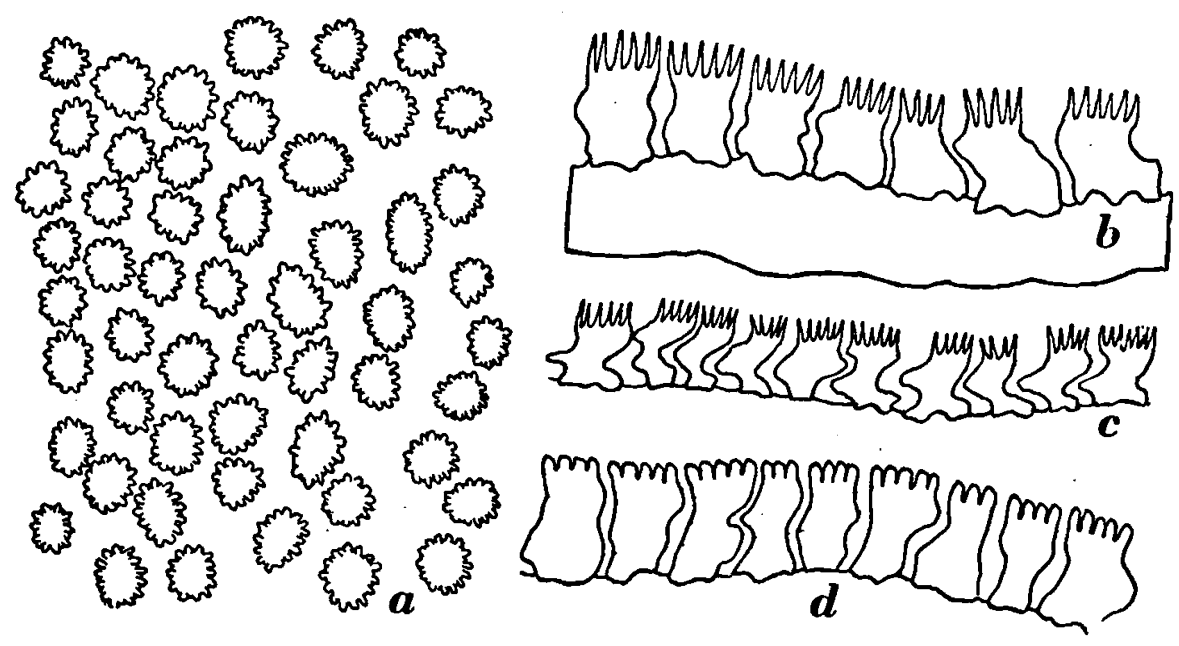

Fig. 5. Loxothylacus ihlei nov. spec. a, excrescences of the external cuticle seen from above; $b$, section of the external cuticle; $c, d$, excrescences of the external cuticle in lateral view. $\times 530$. 
abrasion, have blunt tops (fig. $5 d$ ). The diameter of the excrescences is 7.5 to $15 \mu$; their height is 16 to $26 \mu$.

The internal cuticle of the mantle is rather densely covered with retinacula (fig. 6 a). Each retinaculum consists of a basal part and a comparatively large number ( 8 to 13 ) of spindles (fig. $6 b$ ). In comparison to those of

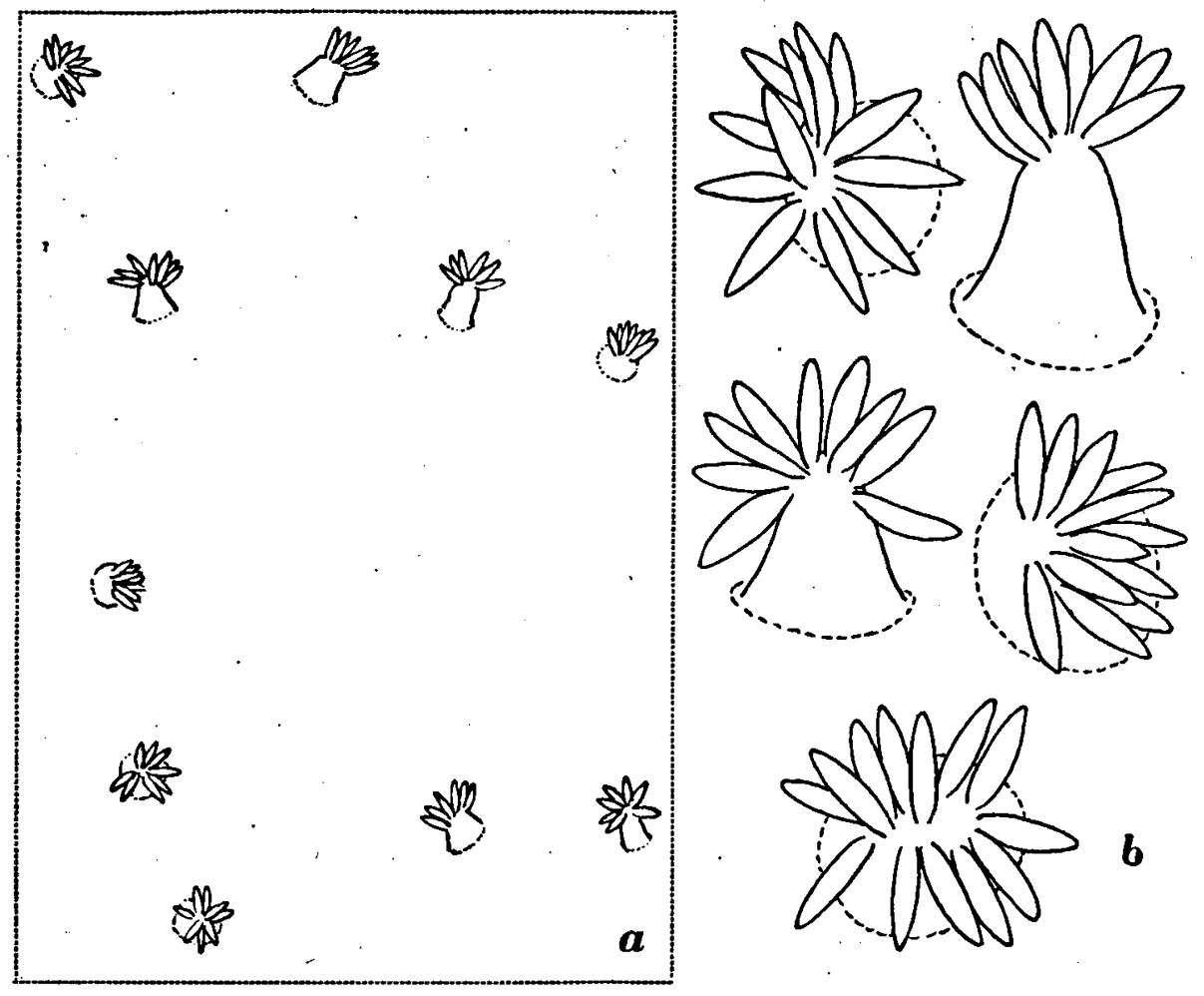

Fig. 6. Loxothylacus ihlei nov. spec. a, retinacula as they occur on the internal cuticle; $b$, retinacula. $a, \times 128 ; b, \times 530$.

other species the spindles are rather large (20 to $26 \mu)$, they do not seem to possess barbs.

In its excrescences of the external cuticle Loxothylacus ihlei shows a great resemblance to $L$. carinatus (Kossm.). In the specimens of $L$. carinatus, which until now could be examined, however, the male organs are not of a so pronouncedly different size, whilst the collecteric glands do not possess more than 60 canals in sections of their most strongly branched region. Moreover, $L$. carinatus differs from $L$. ihlei in the size of the spindles of the retinacula, which in $L$. carinatus have a length of 1o to $14 \mu$, and in $L$. ihlei nearly reach twice this length. Especially the latter character distinctly is of specific value. 